\title{
Growth in Full-Term Small-for-Gestational-Age Infants: From Birth to Final Height
}

\author{
J. KARLBERG AND K. ALBERTSSON-WIKLAND \\ Department of Pediatrics, Queen Mary Hospital, University of Hong Kong [J.K.] and International \\ Pediatric Growth Research Centre, Department of Pediatrics, University of Göteborg, Göteborg, Sweden
}

[K.A.-W.]

\begin{abstract}
Intrauterine growth retardation, or being small for gestational age (SGA), has a life-long impact on a fetus's potential for development and survival. The incidence and relative risk of short stature in children born SGA were studied using a Swedish healthy full-term (37-43 wk of gestation) singleton birth cohort $(n=3650)$ from Göteborg, followed from birth to final height at about 18 y of age. Most infants, defined as SGA on the basis of a birth length less than -2 standard deviation scores (SDS) below the mean ( $\mathrm{SGA}_{\mathrm{L}}$ infants), showed catch-up growth during the first 6 mo after birth, and by 1 y only $13.4 \%$ of the $S_{G A}$ infants were below -2 SDS in height. This percentage decreased further during childhood to reach a value of $7.9 \%$ at $18 \mathrm{y}$ of age. Although most $\mathrm{SGA}_{\mathrm{L}}$ infants have catch-up growth in early life, those who do not constitute $21 \%$ of short, prepubertal children. At $18 \mathrm{y}$ of age, $22 \%$ of the total short population were short at birth $(<-2$ SDS), whereas when birth weight was used to define SGA, only $14 \%$ of the 18 -y-old short population were light at birth. $\mathrm{SGA}_{\mathrm{L}}$ infants were found to have a 7 -fold higher risk for short final stature (relative risk, 7.1; 95\% confidence interval,
\end{abstract}

3.7-13.6) in comparison with the non-SGA $\mathrm{L}_{\mathrm{L}}$ group. In a multiple linear regression analysis, both birth length and mid-parental height were found to be significantly related to the magnitude of catch-up growth from birth to $18 \mathrm{y}$ of age. Neither the length of gestation nor birth weight showed such a relationship. It is concluded that the vast majority $(>86 \%)$ of "healthy" full-term singleton $\mathrm{SGA}_{\mathrm{L}}$ infants will achieve catch-up in height during the first $6-12$ mo of life, and that this is almost independent of whether birth weight or birth length is used to define SGA. Of the remaining, non-catch-up SGA infants, about $50 \%$ remain short in final height, and thus constitute a high risk group for persistent short stature. (Pediatr Res 38: 733-739, 1995)
PHV, peak height velocity
SDS, standard deviation scores
SGA, small for gestational age
SGA $_{W}$, SGA infants with birth weight below -2 SDS
SGA $_{\mathbf{L}}$, SGA infants with birth length below -2 SDS

Abbreviations
Intrauterine growth retardation, or being SGA, has a lifelong impact on a fetus's potential for development and survival (for references, see Refs. 1 and 2). SGA infants have a higher than average risk of morbidity and mortality from many neonatal disorders (3-5). Long-term consequences of SGA have also been described, such as an increased incidence of hypertension, cardiovascular and cerebrovascular disease, and noninsulin-dependent diabetes mellitus in adulthood (6-9). In infants born SGA, there may be persistent short stature in childhood and adulthood (10-16), although most SGA infants (70-90\%) show some degree of catch-up growth during the first years of life (17-19). Detailed information about the relative long-term risk of short stature in SGA infants is not available, nor is it known what proportion of the total short

Received June 6, 1994; accepted May 15, 1995.

Correspondence and reprint requests: Johan Karlberg M.D., Ph.D., B.Sc., Department of Paediatrics, Queen Mary Hospital, University of Hong Kong, Hong Kong.

Supported by grants from the Swedish Medical Research Council $(6465,7509)$, the Faculty of Medicine, University of Hong Kong, and Pharmacia AB. population is represented by SGA infants, as there have been no previous large population-based studies.

The aims of the present study, using a Swedish healthy full-term birth cohort $(n=3650)$ followed from birth to $18 \mathrm{y}$ of age, were to describe the postnatal growth pattern for children defined as SGA by either birth weight or birth length to establish the relative risk of short stature in children born SGA, and to correlate the magnitude of postnatal catch-up growth in SGA infants with other available measures. A preliminary report from this study has been presented previously (20).

\section{METHODS}

Characteristics of the total population. The study population was obtained from 5111 children who were in the last grade of school in 1992 in Göteborg, which has a total population of about 0.5 million and an annual birth rate of $4000-$ 5500 infants. Only 97 girls and 77 boys were unwilling to participate, and another 222 girls and 227 boys failed to attend 
the investigations in school. Of the remaining cohort $(n=$ 4488), $55.8 \%$ were born in Göteborg and another $28.5 \%$ in close proximity to the city. Most of the children were born in 1974 (76.8\%) or 1973 (16.7\%); 3\% were born before 1973 and $3.5 \%$ in 1975 . Boys and girls were equally represented (Table 1). Due to the unique Swedish school system, we had access to an almost complete cohort of children and have no reason to believe that there was any important selection bias in the study population. In Sweden, more than $98 \%$ of children remain within the educational system at 17-19 y of age, including those with mild or moderate mental retardation or other developmental problems.

Data collection. From April to November 1992, the study team visited all schools in Göteborg. The team comprised two school nurses and four specially trained investigators from the International Pediatric Growth Research Centre. All health records from birth to the last grade in school were obtained. They included notes made by doctors and nurses at Child Health Centres (birth to $6 \mathrm{y}$ ) and at schools (7-18 y of age).

At the visit to the schools, all the children were measured (weight and height) in a standardized way with a calibrated Harpenden stadiometer. A questionnaire containing sections on quality of life and previous and present health problems and pharmacologic treatment was completed by each child. At the same time as the parents were informed about the study, they were asked to report their current heights and weights to the school nurse.

Information from the birth and perinatal period, such as size at birth, length of gestation, and any health problems were taken from the Swedish Birth Register at the Swedish National Board for Health and Welfare (21). Gestational age was assessed by the obstetrician, using the first day of the last menstrual period in association with other signs. Thus, the

Table 1. Reasons for omitting a child from the present analysis (more than one reason was present in some children)

\begin{tabular}{lrrr}
\hline Reason for excluding & Girls $(n)$ & Boys $(n)$ & Total $(n)$ \\
\hline At birth & & & \\
Weight/length/gestational & 276 & 253 & 529 \\
$\quad$ age missing & 32 & 26 & 58 \\
Multiple birth & 69 & 73 & 142 \\
Gestation length <37 wk & 9 & 9 & 18 \\
Gestation length $>43 \mathrm{wk}$ & 0 & 1 & 1 \\
Mother diabetic & 0 & 3 & 3 \\
Congenital heart disease & 0 & 1 & 1 \\
CNS haemorrhage & & & \\
At the interview in school & 1 & 0 & 1 \\
Cystic fibrosis & 3 & 7 & 10 \\
Diabetes & 8 & 2 & 10 \\
Endocrine disorder & 7 & 2 & 9 \\
Gluten intolerance & 17 & 11 & 29 \\
Heart disorder & 18 & 7 & 25 \\
Intestinal disorder & 22 & 4 & 26 \\
Kidney disorder & 2 & 2 & 4 \\
Liver disorder & 3 & 1 & 4 \\
Malignancy & 12 & 11 & 23 \\
Seizure & & & \\
Total sample size & 1801 & 1849 & 3650 \\
Sample remaining for & & & \\
$\quad$ analysis & & & \\
\hline
\end{tabular}

gestational age of the study group was estimated in the same way as for the reference population $(22,23)$.

Measuring technique. Both weight and length at birth were measured by trained midwives using exact measuring equipment for length measurements. Both weight and length were recorded repeatedly during the neonatal hospital study, especially in prematurely born and SGA babies. Birth size measuring errors were identified and corrected, and such values were also considered in the newborn record reported to the Swedish Birth Register, which were made at admission from the hospital. Thereafter, the children's weight and length from birth to 2 y of age were measured. Height was measured as supine length until the child could stand up by itself, about $2 \mathrm{y}$ of age. For supine length the child lay fully extended, with heels in contact with a baseboard, and then a movable headboard was brought down on the head. After $2 \mathrm{y}$ of age the child's height was measured by a stadiometer attached to the wall. All height measurements were made to the last completed $0.5 \mathrm{~cm}$. Standing height from about 2 to $6 y$ of age was monitored by skilled personnel at the Child Health Monitoring Centres, and from 7 y by trained school nurses. The measurements taken were routinely plotted in the individual child's growth chart, and extreme values due to, for instance, measuring errors were identified and corrected. The measuring precision at these centers is high, reducing the potential drawback of multicenter measuring. The accuracy of the height measuring scale in each school of our study was also tested, and in $70 \%$ of the schools the difference between the results obtained by the two measuring devices was less than $2 \mathrm{~mm}$.

Selection of study group. The main reason for excluded a child was a lack of information at birth (Table 1), which was the case in 529 children (11.8\%). Almost half $(n=242)$ of these children were not born in Sweden. Another 303 children did not fulfil the inclusion criteria for reasons such as multiple births, prematurity, and/or growth-related disorders (Table 1). Allergic disease (including asthma) was reported in 696 children, but did not exclude children from the analysis. The number of healthy full-term children remaining with growth data both at birth and at the last grade in school was 3650 (1801 girls and 1849 boys). The distribution of gestational age was $8.0,16.6,36.8,21.4,11.9$, and $2.3 \%$ for wk $37,38,39,40,41$, 42 , and 43 , respectively.

Growth data. All growth data were computerized and quality control analysis was performed. For the study group, 52506 height measurements were available from birth to the last examination. There was an average of 14.4 measurements per child; $95 \%$ had $4,85 \%$ had $10,77 \%$ had 13 , and $32 \%$ had 16 height measurements or more.

Age at PHV and final height. A growth chart was produced for each child, and the age at pubertal PHV was defined by visual inspection of the height velocity curve. Such a velocity curve could be constructed for $91.4 \%$ of the children; that is, when four or more height measurements were available during the pubertal period. All the children who had gained less than $0.5 \mathrm{~cm}$ during the past year and who had reached the age at PHV at least 2 y before the last examination were considered to have reached final height. Using this definition, $99.2 \%$ of the children had reached final height at the time the study team 
visited the schools (at about $18 \mathrm{y}$ of age), leaving 3 of the girls and 25 of the boys who had not yet reached their final height. All of the children, however, had reached the age at PHV at least $1.5 \mathrm{y}$ before the last examination, and have only limited growth left. Eight of the girls reported that they had not yet reached menarche.

Ethical approval. The study was approved by the Ethical Committee of the Medical Faculty, University of Göteborg, and by the Swedish Data Authorities. Written informed consent was obtained from the parents and/or those children who were above 16 y of age.

Data analysis. Length and weight at birth were both converted into SDS using the current Swedish reference values for size at birth and adjusting for gender and length of gestation (22). Postnatal body measurements were also expressed in SDS, with the total population of this study serving as the reference population, as the average height for both sexes was 0.2-0.4 SDS above the growth reference values currently used in Sweden (23). These reference values have been reported elsewhere (20). Chronologic age was corrected for the length of gestation; that is, for the number of weeks above or below the usual $40 \mathrm{wk}$ of gestation.

For the total sample $(n=3650)$, the mean height of the fathers was $179.8 \mathrm{~cm}(\mathrm{SD}=6.8 \mathrm{~cm})$ and of the mothers 166.6 $\mathrm{cm}(\mathrm{SD}=6.1 \mathrm{~cm})$; mean mid-parental height was $173.2 \mathrm{~cm}$ $(\mathrm{SD}=5.1 \mathrm{~cm})$. These values were used to compute the parental and mid-parental height SDS, as there has also been a change over time in these figures (24).

Growth data were used from children at birth and at the following approximate ages: $0.5,1,2,5$, and $8 \mathrm{y}$ and at the examination in school, that is at about $18 \mathrm{y}$ of age. Only one examination at each age was included for each child and always the one nearest to the ages specified above (allowing for a maximum of 3-mo difference in early life and 1 y thereafter). For the last examination, the child had to be over $17 \mathrm{y}$ of age.

The age at PHV was converted into SDS using values from the current Swedish growth standard (23), as the design of that study allowed for a more accurate estimation of the age at PHV than the current one; in the previous study, height was measured annually.

Two definitions were used to identify SGA infants; these were a birth weight below $-2 \operatorname{SDS}\left(\mathrm{SGA}_{\mathrm{W}}\right)$ and a birth length below $-2 \operatorname{SDS}\left(\mathrm{SGA}_{\mathrm{L}}\right)$. The relative risk of short stature in later life was computed as the ratio between the percentage of infants who were short at a certain age in the SGA group and in the non-SGA group.

Statistical evaluation. The magnitude of postnatal catch-up growth in $\mathrm{SGA}_{\mathrm{L}}$ infants was correlated with other measures, such as size at birth, mid-parental height, length of gestation, and sex. Statistical analyses also included a $t$ test with an expected value of zero, and the Kruskal-Wallis $k$-sample test for independent observations. Only two-tailed tests were used.

\section{RESULTS}

Incidence of SGA at birth. The incidence (\%) of SGA infants, when using -2 SDS as the cut-off point for either weight or length, is shown in Figure 1 . The majority $(94.6 \%)$

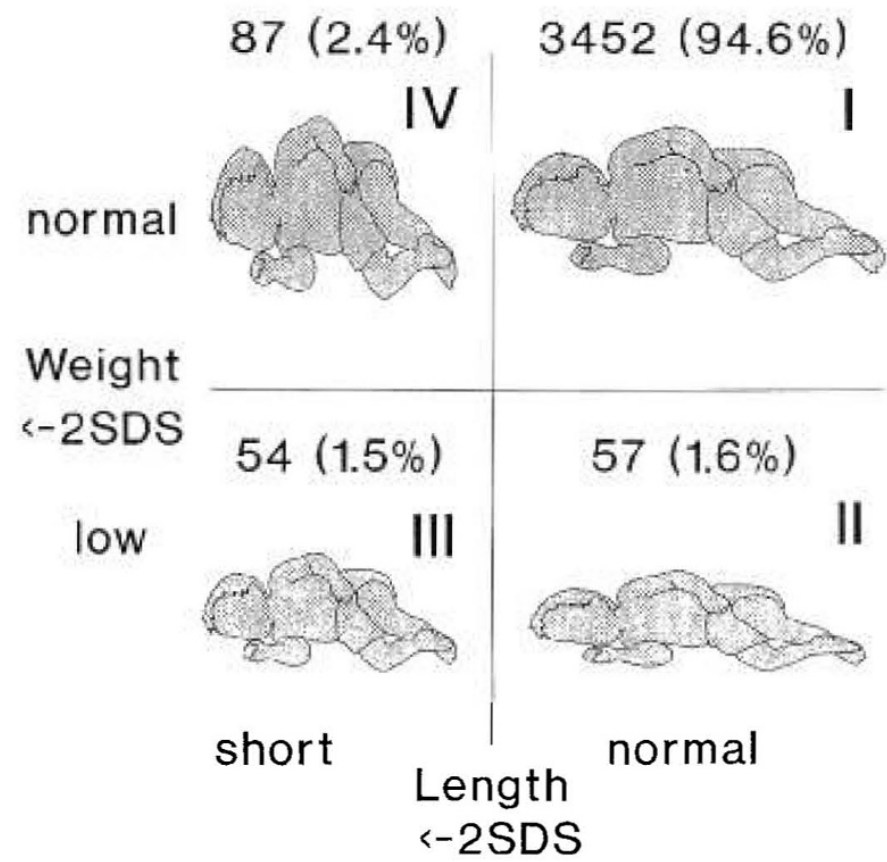

Figure 1. Size at birth adjusted for length of gestation and gender (24). The number and percentage of the infants lying above or below -2 SDS for weight and length are included. Characteristics for each of the four groups (I-IV) are further presented in Table 2 and in Figure 2.

of the infants had a value for both birth weight and length above -2 SDS (group I). The remaining infants fell into three groups according to their size at birth: $1.6 \%$ were of normal length and low weight (group II); $1.5 \%$ were short and of a low weight (group III); and $2.4 \%$ were short and of normal weight (group IV). SGA infants are usually defined only in terms of birth weight (i.e. group II, disproportionate SGA, and group III, proportionate SGA). This definition would not include the short newborn infants of normal weight (group IV), who form the majority $(87 / 141,61.7 \%)$ of the short newborn population.

Postnatal growth for different SGA groups. The pattern of postnatal growth will be described for each of the four individual groups and for combinations of different groups. Table 2 gives the mean and SD values for length of gestation, size at birth, parental height, and age at PHV for each of the four groups. The mean gestational age and the age at PHV were not significantly different between the four groups (Kruskal-Wallis $k$-sample test, $p>0.05$ ), but there were significant differences for mid-parental height SDS, birth weight and birth length ( $p$ $<0.0001)$. The lowest values for mid-parental height SDS and birth length were in group III.

Figure 2 depicts the mean length/height SDS values for the four groups at birth and at $0.5,1,2,5,8$, and $18 \mathrm{y}$ of age, together with the mean parental height SDS; the exact values are given in Table 3 . The postnatal pattern for height was similar in the two groups that were short at birth (groups III and IV representing $\mathrm{SGA}_{\mathrm{L}}$ ); there was an initial rapid and equivalent catch-up growth with a mean increase in SDS of 1.2 and 1.3 , respectively. The mean final height SDS values were -1.0 (group III) and -0.8 (group IV). In comparison, infants in group II were taller at birth with a higher mean birth length $(-1.3 \mathrm{SDS})$, showed less catch-up growth in early postnatal 
Table 2. Clinical characteristics of the four birth size groups and combinations of the four groups

\begin{tabular}{|c|c|c|c|c|c|c|c|c|c|c|c|c|c|c|c|c|c|c|c|c|c|}
\hline \multirow[b]{2}{*}{ Birth size groups* } & \multicolumn{3}{|c|}{$\begin{array}{l}\text { Gestational } \\
\text { length (wk) }\end{array}$} & \multicolumn{3}{|c|}{ Birth weight $(\mathrm{kg})$} & \multicolumn{3}{|c|}{ Birth length $(\mathrm{cm})$} & \multicolumn{3}{|c|}{$\begin{array}{c}\text { Father's height } \\
\text { (SDS) }\end{array}$} & \multicolumn{3}{|c|}{$\begin{array}{l}\text { Mother's height } \\
\text { (SDS) }\end{array}$} & \multicolumn{3}{|c|}{$\begin{array}{l}\text { Midparental } \\
\text { height (SDS) }\end{array}$} & \multicolumn{3}{|c|}{$\begin{array}{l}\text { Age at peak } \\
\text { height velocity } \\
\text { (SDS) }\end{array}$} \\
\hline & $n$ & Mean & $\mathrm{SD}$ & $n$ & Mean & SD & $n$ & Mean & SD & $n$ & Mean & SD & $n$ & Mean & SD & $n$ & Mean & SD & $n$ & Mean & SD \\
\hline Total (I-IV) & 3650 & 40.1 & 1.3 & 3650 & & 0.5 & 3650 & & 2.1 & 2844 & 0.0 & 1.0 & 2926 & 0.0 & 1.0 & 2806 & 0.0 & 1.0 & 3337 & -0.2 & 1.1 \\
\hline-2 & 3452 & .1 & 1.3 & 3452 & 3. & 0.4 & 3452 & 50.7 & 1.9 & 2695 & 0.0 & 1.0 & 2768 & 0.0 & 1.0 & 2657 & 0.0 & 1.0 & 3156 & .2 & 1.1 \\
\hline$<-2$ & 57 & 39.9 & 1.4 & 57 & 2.5 & 0.2 & 57 & 48.1 & 1.2 & 47 & -0.2 & 1.0 & 48 & -0.5 & 0.9 & 47 & -0.4 & 1.0 & 54 & .3 & 1.2 \\
\hline$<-2$ & 54 & 40.5 & 1.4 & 54 & 2.5 & 0.2 & 54 & 45.9 & 1.4 & 41 & -0.5 & 0.9 & 44 & -0.7 & 0.9 & 41 & -0.8 & 1.0 & 47 & .4 & 1.2 \\
\hline IV $\mathrm{H}<-2 \mathrm{~W}>-2$ & 87 & 40.0 & 1.2 & 87 & 2.9 & 0.3 & 87 & 46.2 & 1.1 & 61 & -0.2 & 0.9 & 66 & -0.4 & 1.0 & 61 & -0.3 & 0.9 & 80 & -0.3 & 1.0 \\
\hline $1+1 V$ & 3539 & 40.1 & 1.3 & 3539 & & 0.5 & 3539 & 50 & 2.0 & 2756 & 0.0 & 1.0 & 2834 & 0.0 & 1.0 & 2718 & 0.0 & 1.0 & 3236 & -0.2 & 1.1 \\
\hline $\mathrm{II}+\mathrm{III}\left(\mathrm{SGA}_{\mathrm{W}}\right)$ & 111 & 40.2 & 1.4 & 111 & 2.5 & 0.2 & 111 & 47.0 & 1.7 & 88 & -0.3 & 1.0 & 92 & -0.6 & 0.9 & 88 & -0.6 & 1.0 & 101 & -0.3 & 1.2 \\
\hline $\mathrm{I}+\mathrm{II}$ & 3509 & 40.1 & 1.3 & 3509 & 3.5 & 0.5 & 3509 & & 1.9 & 2742 & & 1.0 & 2816 & 0.0 & 1.0 & 2704 & 0.0 & 1.0 & 3210 & -0.2 & 1.1 \\
\hline $\mathrm{III}+\mathrm{IV}\left(\mathrm{SGA}_{\mathrm{L}}\right)$ & 141 & 40.2 & 1.3 & 141 & 2.8 & 0.3 & 141 & 46.1 & 1.2 & 102 & -0.3 & 0.9 & 110 & -0.5 & 1.0 & 102 & -0.5 & 1.0 & 127 & -0.4 & 1.1 \\
\hline
\end{tabular}

Groups II + III represent the $\mathrm{SGA}_{\mathrm{W}}$ population and III + IV the $\mathrm{SGA}_{\mathrm{L}}$ population. Kruskal-Wallis $k$-sample test showed no significant difference $(p>0.05)$ between the four groups concerning gestational length and age at PHV, but $(p<0.0001)$ for mid-parental height, birth weight and birth length.

* For definitions, see Figure 1 .
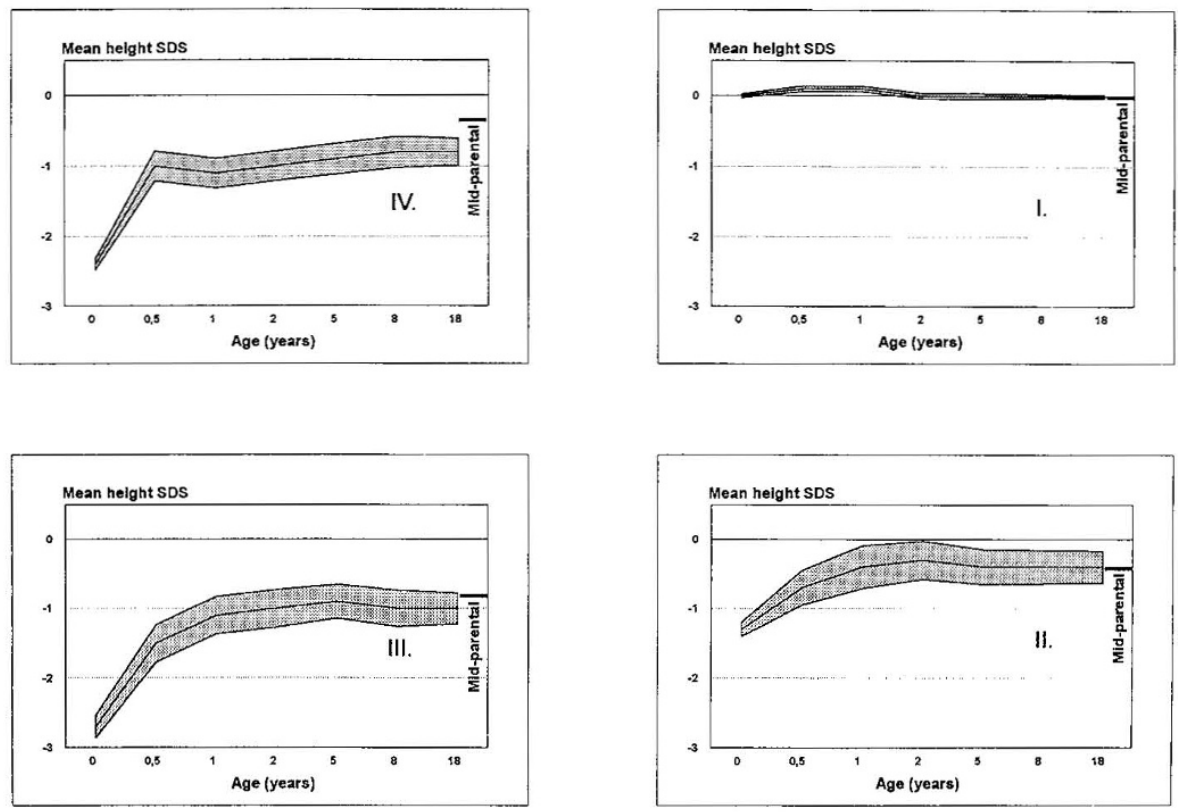

Figure 2. Mean length/height SDS at different ages for the four birth size groups (I-IV) as defined in Figure 1 . The $95 \%$ confidence limit of the mean (mean $\pm 1.96 * \mathrm{SEM})$ is included together with mean mid-parental height.

life (SDS increase of 0.6$)$ and reached a mean final height $(-0.4$ SDS $)$ slightly below the expected one of 0 SDS.

Relative risk of short stature. The incidence of short stature at the specified ages for the SGA and non-SGA groups is given in Table 4 for the $\mathrm{SGA}_{\mathrm{L}}$ group and in Table 5 for the $\mathrm{SGA}_{\mathrm{W}}$ group. For instance, at $2 \mathrm{y}$ of age, $13.4 \%$ of the $\mathrm{SGA}_{\mathrm{L}}$ infants are still short, in comparison with $9.9 \%$ of the $\mathrm{SGA}_{\mathrm{W}}$ infants. For both definitions, most of the catch-up growth was achieved during the first 6 mo of life, and the incidence of short stature in non-SGA children was between 6 and $10 \%$. The main finding was that $7.9 \%$ of the $\mathrm{SGA}_{\mathrm{L}}$ infants at birth had a final height more than 2 SDS below the mean, in comparison with $6.4 \%$ of the $\mathrm{SGA}_{\mathrm{W}}$ infants $\left(\chi^{2}\right.$ test for the two percentages, $p$ $>0.05)$.

The relative risk and $95 \%$ confidence limit of being short at each of the specified ages for SGA children, in comparison with non-SGA children, are also given in Tables 4 and 5 . Slightly higher relative risk values, although nonsignificant ( $p$ $>0.05$ ), were obtained when birth length, rather than birth weight, was used to define SGA (Tables 4 and 5 and Fig. 3). At $18 \mathrm{y}$ of age, there was a 7.1 times greater risk of SGA individuals being short in comparison with non-SGA individuals (using birth weight to define SGA gave a relative risk of 5.2).

Table 4 gives the percentage of all short children at the specified ages who were $\mathrm{SGA}_{\mathrm{L}}$. From 2 y of age and above they represent $27 \%$ of all short children and $22 \%$ at $18 \mathrm{y}$ of age. These figures were lower, though not significantly $\left(\chi^{2}\right.$ test, $p>$ 0.05 ) when birth weight was used to define SGA (Table 5).

In comparison, using the $10 \%$ centile to define SGA gives a relative risk value for attaining a final height below -2 SDS of 7.8 for $\mathrm{SGA}_{\mathrm{L}}$ infants and 4.0 for SGA infants. 
Table 3. Length/height SDS at different ages for the four birth size groups and combinations of the four groups

\begin{tabular}{|c|c|c|c|c|c|c|c|c|c|c|c|c|c|c|c|c|c|c|c|c|c|}
\hline \multirow[b]{3}{*}{ Birth size groups* } & \multicolumn{21}{|c|}{ Length/height SDS } \\
\hline & \multicolumn{3}{|c|}{ At birth } & \multicolumn{3}{|c|}{ At $0.5 \mathrm{y}$} & \multicolumn{3}{|c|}{ At $1 \mathrm{y}$} & \multicolumn{3}{|c|}{ At $2 y$} & \multicolumn{3}{|c|}{ At $5 \mathrm{y}$} & \multicolumn{3}{|c|}{ At $8 \mathrm{y}$} & \multicolumn{3}{|c|}{ At $18 y$} \\
\hline & $n$ & Mean & $\mathrm{SD}$ & $n$ & Mean & SD & $n$ & Mean & SD & $n$ & Mean & $\mathrm{SD}$ & $n$ & Mean & $\mathrm{SD}$ & $n$ & Mean & $\mathrm{SD}$ & $n$ & Mean & $\mathrm{SD}$ \\
\hline Total (I-IV) & 3650 & -0.1 & 1.1 & 3054 & 0.0 & 1.0 & 2990 & 0.0 & 1.0 & 2878 & 0.0 & 1.0 & 3094 & 0.0 & 1.0 & 3370 & 0.0 & 1.0 & 3635 & 0.0 & 0.9 \\
\hline I $\mathrm{H}>-2 \mathrm{~W}>-2$ & 3452 & 0.0 & 1.0 & 2888 & 0.1 & 1.0 & 2825 & 0.1 & 1.0 & 2718 & 0.0 & 1.0 & 2925 & 0.1 & 1.0 & 3189 & 0.1 & 1.0 & 3439 & 0.0 & 0.9 \\
\hline II $\mathrm{H}>-2 \mathrm{~W}<-2$ & 57 & -1.3 & 0.4 & 48 & -0.7 & 0.9 & 48 & -0.4 & 1.1 & 48 & -0.3 & 1.0 & 49 & -0.4 & 0.9 & 54 & -0.4 & 0.9 & 57 & -0.4 & 0.9 \\
\hline III $\mathrm{H}<-2 \mathrm{~W}<-2$ & 54 & -2.7 & 0.6 & 44 & -1.5 & 0.9 & 43 & -1.1 & 0.9 & 43 & -1.0 & 0.9 & 44 & -0.9 & 0.8 & 47 & -1.0 & 0.9 & 53 & -1.0 & 0.8 \\
\hline IV $\mathrm{H}<-2 \mathrm{~W}>-2$ & 87 & -2.4 & 0.4 & 74 & -1.0 & 0.9 & 74 & -1.1 & 0.9 & 69 & -1.0 & 0.9 & 76 & -0.9 & 1.0 & 80 & -0.8 & 1.0 & 86 & -0.8 & 0.9 \\
\hline$I+I V$ & 3539 & 0.0 & 1.0 & 2962 & 0.1 & 1.0 & 2899 & 0.0 & 1.0 & 2787 & 0.0 & 1.0 & 3001 & 0.0 & 1.0 & 3269 & 0.0 & 1.0 & 3525 & 0.0 & 0.9 \\
\hline $\mathrm{II}+\mathrm{III}\left(\mathrm{SGA}_{\mathrm{W}}\right)$ & 111 & -2.0 & 0.9 & 92 & -1.0 & 1.0 & 91 & -0.7 & 1.0 & 91 & -0.7 & 1.0 & 93 & -0.6 & 0.9 & 101 & -0.7 & 1.0 & 110 & -0.7 & 0.9 \\
\hline $\mathrm{I}+\mathrm{II}$ & 3509 & 0.0 & 1.0 & 2936 & 0.1 & 1.0 & 2873 & 0.1 & 1.0 & 2766 & 0.0 & 1.0 & 2974 & 0.0 & 1.0 & 3243 & 0.0 & 1.0 & 3496 & 0.0 & 0.9 \\
\hline $\mathrm{III}+\mathrm{IV}\left(\mathrm{SGA}_{\mathrm{L}}\right)$ & 141 & -2.5 & 0.5 & 118 & -1.2 & 0.9 & 117 & -1.1 & 0.9 & 112 & -1.0 & 0.9 & 120 & -0.9 & 0.9 & 127 & -0.9 & 1.0 & 139 & -0.9 & 0.8 \\
\hline
\end{tabular}

Groups II + III represent the $\mathrm{SGA}_{\mathrm{W}}$ population and III + IV the $\mathrm{SGA}_{\mathrm{L}}$ population.

* For definitions, see Figure 1.

Table 4. The incidence (in \%) of shortness at different ages in $S G A_{L}$ infants and in non-SGA $A_{L}$ infants

\begin{tabular}{|c|c|c|c|c|c|c|c|c|c|}
\hline \multirow[b]{3}{*}{ Mean age (y) } & \multicolumn{3}{|c|}{ Birth length $\leq 2$ SDS (III + IV) } & \multicolumn{3}{|c|}{ Birth length $\geq 2$ SDS $(\mathrm{I}+\mathrm{II})$} & \multirow[b]{3}{*}{$\mathrm{RR}$} & \multirow{3}{*}{$\begin{array}{c}\text { RR } 95 \% \\
\text { CI }\end{array}$} & \multirow{3}{*}{$\begin{array}{l}\mathrm{SGA}_{\mathrm{L}} \text { of all } \\
\text { short } \\
\text { children } \%\end{array}$} \\
\hline & \multirow{2}{*}{$\begin{array}{l}\text { Total number } \\
(n)\end{array}$} & \multicolumn{2}{|c|}{ Short $\leq 2$ SDS } & \multirow{2}{*}{$\begin{array}{c}\text { Total number } \\
n\end{array}$} & \multicolumn{2}{|c|}{$\begin{array}{c}\text { Short } \leq 2 \\
\text { SDS }\end{array}$} & & & \\
\hline & & $n$ & $\%$ & & $n$ & $\%$ & & & \\
\hline Birth & 140 & 140 & 100.00 & 3515 & 0 & 0.00 & - & - & - \\
\hline 0.5 & 118 & 20 & 16.95 & 2937 & 45 & 1.53 & 11.1 & $6.8-18.1$ & 30.8 \\
\hline 1 & 117 & 16 & 13.68 & 2874 & 42 & 1.46 & 9.4 & $5.4-16.1$ & 27.6 \\
\hline 2 & 112 & 15 & 13.39 & 2767 & 40 & 1.45 & 9.2 & $5.3-16.3$ & 27.3 \\
\hline 5 & 120 & 10 & 8.33 & 2975 & 42 & 1.41 & 5.9 & $3.0-11.5$ & 19.2 \\
\hline 8 & 127 & 13 & 10.24 & 3244 & 49 & 1.51 & 6.8 & $3.8-12.2$ & 21.0 \\
\hline 18 & 139 & 11 & 7.91 & 3497 & 39 & 1.12 & 7.1 & $3.7-13.6$ & 22.0 \\
\hline
\end{tabular}

The relative risk (RR) for shortness in $\mathrm{SGA}_{\mathrm{L}}$ in relation to non-SGA $\mathrm{A}_{\mathrm{L}}$ is also given together with the $95 \%$ confidence interval (CI). The percent of all short children represented by the $\mathrm{SGA}_{\mathrm{L}}$ children is included.

Table 5. The incidence (in \%) of shortness at different ages in $S G A_{W}$ infants and in non-SGA $A_{W}$ infants

\begin{tabular}{|c|c|c|c|c|c|c|c|c|c|}
\hline \multirow[b]{3}{*}{ Mean age (y) } & \multicolumn{3}{|c|}{ Birth length $<-2$ SDS (III + IV) } & \multicolumn{3}{|c|}{ Birth length $>-2 \operatorname{SDS}(\mathrm{I}+\mathrm{II})$} & \multirow[b]{3}{*}{$\mathrm{RR}$} & \multirow{3}{*}{$\begin{array}{c}\mathrm{RR}(95 \% \\
\mathrm{CI})\end{array}$} & \multirow{3}{*}{$\begin{array}{c}\mathrm{SGA}_{\mathrm{W}} \text { of all } \\
\text { short } \\
\text { children }(\%)\end{array}$} \\
\hline & \multirow{2}{*}{$\begin{array}{c}\text { Total number } \\
(n)\end{array}$} & \multicolumn{2}{|c|}{$\begin{array}{l}\text { Short }<-2 \\
\text { SDS }\end{array}$} & \multirow{2}{*}{$\begin{array}{c}\text { Total number } \\
n\end{array}$} & \multicolumn{2}{|c|}{$\begin{array}{c}\text { Short }<-2 \\
\text { SDS }\end{array}$} & & & \\
\hline & & $n$ & $\%$ & & $n$ & $\%$ & & & \\
\hline Birth & 111 & 54 & 48.65 & 3539 & 87 & 2.46 & 19.8 & $14.9-26.2$ & 38.3 \\
\hline 0.5 & 92 & 14 & 15.22 & 2965 & 51 & 1.72 & 8.8 & $5.1-15.4$ & 21.5 \\
\hline 1 & 91 & 9 & 9.89 & 2902 & 49 & 1.69 & 5.9 & $3.0-11.6$ & 15.5 \\
\hline 2 & 91 & 9 & 9.89 & 2790 & 46 & 1.65 & 6.0 & $3.0-11.9$ & 16.4 \\
\hline 5 & 93 & 4 & 4.30 & 3004 & 48 & 1.60 & 2.7 & $1.0-7.3$ & 7.7 \\
\hline 8 & 101 & 8 & 7.92 & 3272 & 54 & 1.65 & 4.8 & $2.4-9.8$ & 12.9 \\
\hline 18 & 110 & 7 & 6.36 & 3528 & 43 & 1.22 & 5.2 & $2.4-11.3$ & 14.0 \\
\hline
\end{tabular}

The relative risk (RR) for shortness in $\mathrm{SGA}_{\mathrm{W}}$ in relation to non-SGA $\mathrm{W}$ is also given together with the $95 \%$ confidence interval (CI). The percent of all short children represented by the $\mathrm{SGA}_{\mathrm{W}}$ children is included.

Predictors for catch-up growth. The catch-up growth in groups III and IV (SGA $)$ was analysed in relation to birth length SDS, length of gestation, sex, birth weight SDS, and mid-parental height SDS. The increases in height SDS from birth to 6 mo of age and from birth to $18 \mathrm{y}$ of age were used as the dependent variables in a linear regression analysis and the other five measures as mentioned above the independent variables. The gain in height SDS from birth to 6 mo of age was significantly related to birth length SDS $(p<0.05)$ and length of gestation $(p<0.01)$, but not to the sex of the child, mid-parental height SDS or birth weight SDS $(p>0.05)$. The multiple $R^{2}$ value was 0.15 ( $p<0.02$ ). Mid-parental height SDS $(p<0.0001)$ and birth length SDS $(p<0.0001)$ were the two measures significantly related to the gain in height SDS from birth to $18 \mathrm{y}$ of age, giving a multiple $R^{2}$ of 0.53 ( $p<$ 0.0001).

\section{DISCUSSION}

To our knowledge, this is the first large longitudinal population-based study to describe the incidence of short stature from birth to adult height in individuals born SGA and the 
Relative risk of being short (<-2SDS)

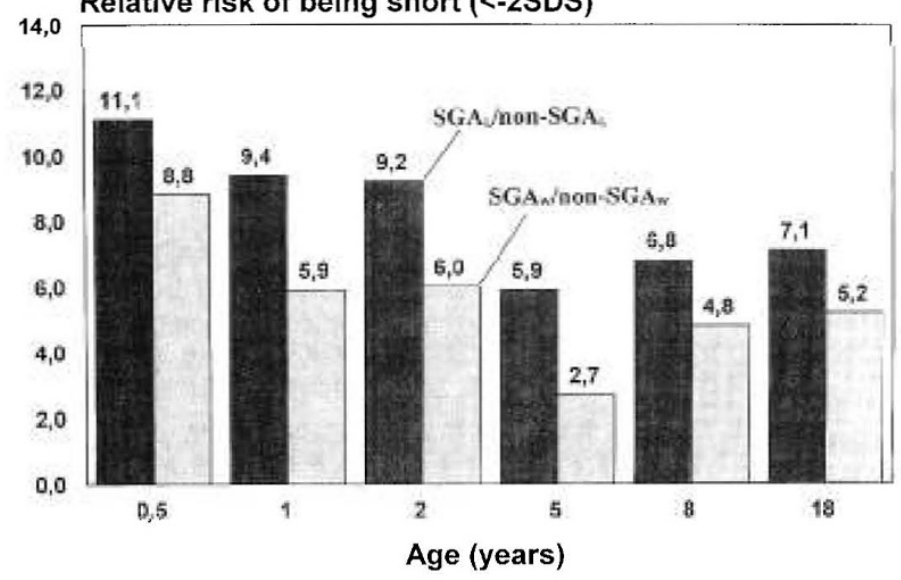

Figure 3. The relative risk of being short at different ages for SGA infants in relation to non-SGA infants. The ratio is given for the two SGA definitions used, i.e. a birth length below -2 SDS $\left(\mathrm{SGA}_{\mathrm{L}}\right)$ or a birth weight below -2 $\operatorname{SDS}\left(\mathrm{SGA}_{\mathrm{W}}\right)$.

proportion of the total short population that is represented by SGA infants. The results also provide new information on postnatal catch-up growth, such as its timing and correlation with other variables.

Study population. The results are based on "healthy" fullterm singleton Swedish children, born mainly in Göteborg and its surroundings. The reason for not including premature SGA children or children with certain disorders was to exclude other possible external influences on growth. Due to the unique Swedish educational system we have had access to an almost complete cohort of children of about $18 \mathrm{y}$ of age. We have no reason to believe that there is any important selection bias in the study population. Of the total target population of 5111, $87.7 \%$ were included in the study; a small proportion of the remainder were unwilling to participate, whereas others failed to attend the investigation in school. It has not been possible to compare the background characteristics of the nonparticipating children with those participating in the study, owing to the regulations of the Swedish Data Authority. There is no reason to believe, however, that the relatively low dropout rate had a significant influence on the major findings presented, because virtually all Swedish children still belong to the "ordinary" educational system at 17-19 y of age. Out of the study population $(n=4488), 18.7 \%$ did not fulfill the inclusion criteria for the present study; $6.8 \%$ were excluded for medical reasons and $6.8 \%$ for multiple births, prematurity and/or growth-related disorders. Data at birth was missing in $11.9 \%$ of the children, and almost half of these were not born in Sweden. It was concluded, therefore, that the children used in the analyses were representative of healthy full-term singleton Swedishborn children.

The fluctuations in sample size over time, due to height measurements not being available for all children at all ages, may be the reason for some of the fluctuations in the incidence, relative risk, and the mean SDS values recorded. Values were, however, available for all children at birth and for almost all at 17-19 y of age, when the vast majority had fulfilled the criteria for final height; these ages were the most important in the present study. Also measuring errors could have caused such fluctuations, but this cannot be of any major importance in the present study. Since 1971 measurements are taken routinely in Sweden from birth to the last grade in school using standardized equipments and measuring techniques. All values should have been plotted in a growth chart followed by the inspection (and action) of a physician. All computerized charts in the present study were inspected by the study team, and a few extreme growth patterns were then identified. They were most frequently related to recording/punching errors of the date at examination.

Postnatal growth for different SGA groups. SGA infants are usually defined in terms of birth weight alone, including both disproportionate and proportionate $\mathrm{SGA}_{\mathrm{W}}$. Using this definition, infants in groups II and III (Fig. 1) would together form the SGA population, which would not include the short newborn infants of normal weight (group IV). Omission of group IV would, however, have a major influence on the results, especially when the outcome is the postnatal gain in height, as we found that the majority $(61.7 \%)$ of the short newborn population belonged to group IV. This is illustrated by the catch-up pattern for height, which was different in the disproportionate and proportionate $\mathrm{SGA}_{\mathrm{W}}$ groups (Fig. 2), but similar in the two groups that were short at birth (normal or subnormal weight).

In defining SGA infants, the choice of reference values is important. As heights have increased in Sweden over the last decades, we used for birth (23) and, postnatally, our updated growth reference values based on the healthy full-term children included in the present work (21). These updated growth reference values should be valid for the current newborn, childhood, and adult Swedish populations.

It is difficult to compare the results of this study with those of other similar studies, as there are differences in definition of the study population. Previous studies have commonly been hospital-based and thus may have included an increased number of risk pregnancies. Differences in obstetric and perinatal handling (4) may also have an impact. Another source of difference is that different definitions of SGA have been used; it is more usual to define SGA in terms of birth weight than of birth length. Different cutoff levels have also been employed, such as -2 SDS, the 3 rd or 10 th centile, or $2500 \mathrm{~g}$ (26). One study population will therefore not necessarily be similar to another study population. The year and the country in which the study was undertaken may also contribute to differences in the results. Also, the secular trend of increases in height over generations will affect growth reference values and cutoff points (26).

A continuous scale would certainly be more appropriate than using a certain cut-off point, but we feel that the data at least initially should be presented in the clinically traditional way in terms of a cutoff point. We have chosen to use -2 SDS as cutoff point, as this is currently used in the definition of shortness. Using for example, the 10th centile would have increased the SGA population approximately 4-fold, resulting in a decreased sensitivity in defining shortness in older children. 
Relative risk of short stature. It is known that postnatal catch-up growth in SGA infants occurs mainly during the first year of life (17). In the present study, most infants showed catch-up growth during the first $6 \mathrm{mo}$, and by $1 \mathrm{y}$ of age only $13.4 \%$ of the SGA infants were below -2 SDS in height. This figure decreased further during childhood to reach a value of $7.9 \%$ at $18 \mathrm{y}$ of age, indicating an ongoing, slow catch-up growth. Similar incidence figures were obtained when SGA was defined in terms of birth weight; for instance, at $18 \mathrm{y}$ the incidence was $6.4 \%$. It can be concluded that the majority $(>86 \%)$ of healthy full-term singleton SGA infants will catch-up in height during the first 6-12 mo of life and that this is almost independent of whether birth weight or birth length is used in defining SGA. Of the remaining SGA infants, about half will remain short, thus constituting a high risk population for persistent short stature.

The early rapid catch-up growth pattern described here is consistent with the results of other studies, as is the incidence of short stature in childhood (17), but previously there has been little or no information on final adult height in SGA infants. At $18 \mathrm{y}$ of age, $22 \%$ of our short total population were short at birth, although the figures were lower when using birth weight to define SGA (e.g. $14 \%$ at $18 \mathrm{y}$ of age).

Although most SGA infants have catch-up growth in early life, those who do not constitutes a significant proportion of the short population of both children and adults. Insults in early life may thus have life-long consequences, such as persistent short stature, although it should be remembered that some infants have short parents and therefore have a genetic predisposition to be short. In the present study, SGA infants had a 7-fold higher risk of short stature in adulthood (relative risk of 7.1) in comparison with the non-SGA group. Interestingly, a similar 7-fold increased risk has been reported for hypertension, cardiovascular and cerebrovascular disease, and noninsulin-dependent diabetes mellitus in adults who were born SGA, although the SGA definitions used were slightly different $(6-9)$. It seems reasonable, therefore, to follow growth in SGA infants for at least the first $2 \mathrm{y}$ of life, and where little or no catch-up growth occurs to undertake investigations to rule out treatable conditions.

Predictors for catch-up growth. Both birth length and midparental height were significantly correlated with the magnitude of catch-up growth between birth and $18 \mathrm{y}$ of age. Neither the length of gestation nor birth weight, however, showed such a relationship. Other studies have demonstrated that birth weight adjusted for birth length is related to the pattern of postnatal catch-up growth, but this could not be confirmed in the present study when comparing the three SGA groups (I, II, and III) $(11,18)$.

It can be concluded that the majority ( $>86 \%$ ) of healthy full-term singleton SGA infants will exhibit a catch-up in height during the first $6-12$ mo of life and that this is almost independent of whether birth weight or birth length is used to define SGA. Of the remaining SGA infants, about half will be short in final height, thus constituting a high-risk population for persistent short stature, equivalent to $22 \%$ of the short population.

Acknowledgments. The authors are grateful to the schoolnurses Hedvig Dahlquist and Margita Peterson, the study team of Ingela Larsson, Annika Olsson, Barbro Samuelsson, and Lena Wirén, and the computer skills of Anita Ericson, Helene Olsson and Birgitta Svensson. For valuable support we are grateful to Dr. Anders Mark and Siv Ehnberg. We are also grateful to the staff and students (second grade in 1992) of the schools of Göteborg.

\section{REFERENCES}

1. Barker DJP 1993 The intrauterine origins of cardiovascular disease. Acta Paediat Suppl 391:93-99

2. Gluckman PD 1993 Intrauterine growth retardation: future research directions. Acta Paediatr 388:96-99

3. Fitzhardinge PM, Steven EM 1972 The small-for-date infant. II. Neurologic and intellectual sequelae. Pediatrics 50:50-57

4. Wennergren M, Wennergren G, Vilbergsson G 1988 Obstetric characteristics and neonatal performance in a four-year small for gestational age population. Obstet Gynecol 72:615-620

5. Low JA, Galbraith RS, Muir D et al. 1978 Intrauterine growth retardation. A preliminary report of long-term morbidity. Am J Obstet Gynecol 30:534-545

6. Hales CN, Barker DJP 1992 Type 2 (non-insulin-dependent) diabetes mellitus: the thrifty phenotype hypothesis. Diabetologia 35:595-601

7. Lever A, Harrap S 1992 Essential hypertension: a disorder of growth with origins in childhood. J Hypertens 10:101-120

8. Barker DJP, Winter PD, Osmond C, Margetts B 1989 Weight in infancy and death from ischaemic heart disease. Lancet 2271:577-580

9. Phipps K, Barker DJP, Hales CN, Fall CHD, Osmond C, Clark PMS 1993 Fetal growth and impaired glucose tolerance in men and women. Diabetologia 36:225-228

10. Fitzhardinge PM, Steven EM 1972 The small-for-date infant. I. Later growth patterns Pediatrics 49:671-681

11. Villar J, Smeriglio V, Martorell R, Brown CH, Klein RE 1984 Heterogeneous growth and mental development of intrauterine growth retarded infants. Pediatrics 74:783791

12. Bhargova N, Jumari S, Chaudhury P 1982 Outcome of low birth weight infants. Acta Paediatr Scand 73:406-407

13. Davies DP 1982 Growth of small-for-dates babies. Early Hum Dev 5:95-105

14. Westwood M, Kramer MS, Munz D, Lovett JM, Walters GV 1983 Growth and development of full-term nonasphyxiated small-for-gestational-age newborns: follow up through adolescence. Pediatrics 71:376-382

15. Job JC, Rolland A 1986 Histoire naturelle des retards de croissance à début intrautérin. Arch Fr Pediatr 43:300-306

16. Fizhardinge PM, Inwood S 1989 Long-term growth in small-for-date children. Acta Paediatr Scand Suppl 349:27-33

17. Albertsson-Wikland $\mathrm{K}$, Wennergren $\mathrm{G}$, Wennergren $\mathrm{M}$, Vilbergsson $\mathrm{G}$, Rosberg $\mathrm{S}$ 1993 Longitudinal follow-up of growth in children born small for gestational age. Acta Paediatr 82:438-443

18. Tenovuo A, Kero P, Piekkala P, Korvenrata H, Sillanpaa M, Erkkola R 1987 Growth of 519 small for gestational age infants during the first two years of life. Acta Paediatr Scand 76:636-646

19. Ounsted M, Moar V, Scott A 1982 Growth in the first four years: II. Diversity within groups of small-for-dates and large-for-dates babies. Early Hum Dev 7:29-39

20. Albertsson-Wikland K, Karlberg J 1994 Natural growth in children born small-forgestational-age (SGA) with and without catch-up growth. Acta Paediatr Suppl 399:64-70

21. Medical birth registry 1973-1986. Statistics of the National Board of Health and Welfare. Statistical Reports HS 1977; 16: 1980; 2, 1981;2, 1983; 5, 1984; 2. National Central Bureau of Statistics, Stockholm, Sweden

22. Niklasson A, Ericson A, Fryer J, Karlberg J, Lawrence C, Karlberg P 1991 An update of the Swedish reference standards for weight, length and head circumference at birth for given gestational age (1977-1981). Acta Paediatr Scand 80:756-762

23. Karlberg P, Taranger J, Engström I, Lichtenstein H, Svennberg-Redegren I 1976 The somatic development of children in a Swedish urban community. Acta Paediatr Scand Suppl 258:7-76

24. Karlberg J and Fryer JG 1990 A method for adjustment of final height for midparental height for Swedish children. Acta Paediatr Scand 79:468-469

25. Kramer MS 1987 Determinants of low birth weight: methodological assessment and meta-analysis. Bull World Org 65:663-737

26. Eveleth PB, Tanner JM. Worldwide Variation in Human Growth. Cambridge University Press, UK 